\title{
A treatment dilemma in adult immunoglobulin A nephropathy: what is the appropriate target, preservation of kidney function or induction of clinical remission?
}

\author{
Hirokazu Imai · Naoto Miura
}

Received: 19 July 2011/Accepted: 12 October 2011/Published online: 16 November 2011

(C) The Author(s) 2011. This article is published with open access at Springerlink.com

\begin{abstract}
Immunoglobulin (Ig) A nephropathy is the most common type of glomerulonephritis worldwide. Data on its natural history suggest that approximately $40 \%$ of patients progress to end-stage renal failure after 20 years. Various therapies such as antiplatelet medication, fish oil, oral prednisolone, intravenous prednisolone, tonsillectomy, and tonsillectomy plus steroid pulse (TSP) have been proposed. Japanese nephrologists face challenging issues regarding this disease, such as the usefulness of the annual urinary screening system (kenshin) and kidney biopsies, the desire of patients and their families for treatment despite insufficient clinical evidence, and the risk of overtreatment with TSP versus the loss of a 'golden period' with late intervention. We review the current literature on tonsillectomy, steroid therapy, and TSP, which was first proposed in Japan, and present some perspectives on the treatment of IgA nephropathy.
\end{abstract}

Keywords IgA nephropathy - Steroid therapy ·

Tonsillectomy - Tonsillectomy plus steroid pulse therapy (TSP)

\section{Introduction}

More than 40 years have passed since immunoglobulin (Ig) A nephropathy was first described by Berger and Hinglais

H. Imai $(\varangle) \cdot$ N. Miura

Division of Nephrology and Rheumatology,

Department of Internal Medicine,

Aichi Medical University School of Medicine,

Nagakute-cho, Aichi 480-1195, Japan

e-mail: imaihiro@aichi-med-u.ac.jp in 1968 [1]. Various approaches such as antiplatelet medication, fish oil, oral prednisolone, intravenous prednisolone, tonsillectomy, and tonsillectomy plus steroid pulse therapy (TSP), have been proposed for treating patients with adult IgA nephropathy. Clinicians often face challenges in deciding which treatment is most suitable for each patient, while balancing the hopes of patients and their families with insufficient clinical evidence. Here we review the data from clinical trials and give a perspective on the treatment of IgA nephropathy.

\section{What is the treatment dilemma for Japanese nephrologists?}

Are the annual urinary screening system (kenshin) and kidney biopsies useful?

A Japanese law established a system of annual urinary screening (kenshin) in schools and workplaces approximately 40 years ago. About $40 \%$ of the Japanese population receive kenshin each year. Persons with detected urinary abnormalities are advised to consult local physicians. If a local physician finds $>1+$ proteinuria on repeat urinary testing, he refers the patient to a nephrologist. Approximately 10,000 kidney biopsies are performed each year in Japan, of which 30-40\% (3,000-4,000 persons) receive a diagnosis of $\operatorname{IgA}$ nephropathy. Many patients with IgA nephropathy are diagnosed at an early stage in Japan. The benefit of kenshin and kidney biopsies depends on whether early intervention can improve the prognosis of IgA nephropathy. The Ministry of Health, Labour and Welfare of Japan requires the Japanese Society of Nephrology to demonstrate the efficacy of kenshin; however, Japanese nephrologists are not currently able to do so. 
The desire of patients and their families

versus insufficient clinical evidence

Since TSP was first reported by Hotta et al. in 2001 [2], a recent analysis revealed that 600 patients in Japan received TSP in 2006. More than one thousand patients received TSP in 2010. One year after TSP, 50\% of patients achieved clinical remission (CR), defined as no urinary abnormalities [3]. Many patients and their families, having discovered information about the efficacy of TSP through the Internet or personal communications, visit the hospital to seek TSP. Although many Japanese nephrologists know that several international guidelines do not recommend TSP for IgA nephropathy, they are challenged with making decisions on which treatment is suitable for the patient, while balancing the desire of patients and their families against insufficient clinical evidence.

A risk of overtreatment versus a lost 'golden period'

Many Japanese nephrologists feel that patients with earlystage or mild IgA nephropathy respond readily to TSP or steroid pulse therapy. On the other hand, patients with proteinuria $>1.0 \mathrm{~g} /$ day and creatinine clearance $(\mathrm{CCr})$ $<70 \mathrm{ml} / \mathrm{min}$ are resistant not only to TSP but also to oral steroid therapy. The 'golden period' exists when patients have proteinuria $<1.0 \mathrm{~g} / \mathrm{day}$.

Preservation of kidney function versus induction of clinical remission

The goal of many clinical studies is the preservation of renal function. However, Hotta et al. emphasized that TSP can induce CR and demonstrated that patients who respond to TSP could maintain their kidney function. Some Japanese nephrologists are shifting from a paradigm of preserving kidney function to inducing $\mathrm{CR}$.

\section{What is the overall natural history of IgA nephropathy?}

Chauveau and Droz [4] studied the natural history of IgA nephropathy in 1993. In a series of 119 patients with biopsy-proven IgA nephropathy from 1968 to 1972 at Necker Hospital, 74 patients (44 men and 30 women) received no therapy. Of this subset, 22 patients $(29.7 \%)$ showed spontaneous remission, defined as no urinary abnormalities and normal kidney function, 24 patients $(32.4 \%)$ had urinary abnormalities without aggravation of kidney function, and 28 patients $(37.8 \%)$ progressed to end-stage renal failure during a 20 -year observation period (Table 1).
Table 1 A natural history of $\operatorname{IgA}$ nephropathy at Necker Hospital

\begin{tabular}{ll}
\hline & $\begin{array}{l}\text { Chauveau and } \\
\text { Droz }\end{array}$ \\
\hline Observation period & 20 years \\
Number of patients & 74 \\
Spontaneous remission & $29.7 \%$ \\
Persistent urinary abnormalities without & $32.4 \%$ \\
$\quad$ aggravation of kidney function & \\
End-stage renal failure & $37.8 \%$ \\
\hline
\end{tabular}

\section{Do patients with mild or early-stage IgA nephropathy recover or progress?}

Szeto et al. reported on the natural history of mild or earlystage IgA nephropathy in patients with proteinuria $<0.4 \mathrm{~g} /$ day over an observation period of 7 years [5]. About $40 \%$ of these patients showed a progressive course-33\% had proteinuria increased to $>1.0 \mathrm{~g} / \mathrm{day}$, and $7 \%$ had decreased kidney function defined as $\mathrm{CCr}<70 \mathrm{ml} / \mathrm{min} / 1.73 \mathrm{~m}^{2}$. Another $42 \%$ of patients had persistent proteinuria and hematuria; however, $14 \%$ of patients reached CR that the authors defined as the disappearance of hematuria (Table 2).

Shen et al. also analyzed the natural history of $\operatorname{IgA}$ nephropathy with isolated microscopic hematuria, defined as no detection of urinary protein by dipstick [6]. They compared patients with no proteinuria $(<0.03 \mathrm{~g} /$ day $)$ and microalbuminuria (0.03-0.30 g/day): the $\mathrm{CR}$ rate (disappearance of hematuria) was 22 versus $6 \%$ ( $p=0.005)$, the incidence of increased proteinuria was 6 versus $42 \%(p<0.0001)$, hypertension was 12 versus $44 \%$ ( $p=0.0001$ ), and impaired kidney function [glomerular filtration rate (GFR) $<60 \mathrm{ml} /$ $\min / 1.73 \mathrm{~m}^{2}$ ] was 4 versus $29 \%(p=0.0042)$, respectively. They demonstrated that microalbuminuria was one of the prognostic factors in IgA nephropathy with isolated microscopic hematuria (Table 2).

\section{Does oral prednisolone therapy improve the outcome of IgA nephropathy?}

In 1996, Kobayashi et al. [7] evaluated the efficacy of oral steroid therapy for patients with $\operatorname{IgA}$ nephropathy. Their retrospective cohort study tracked the prognosis of 20 patients who received oral steroid therapy and 26 patients who did not receive steroid therapy for 10 years. All patients in both groups had persistent baseline proteinuria ranging between 1.0 and $2.0 \mathrm{~g} / \mathrm{day}$. In the steroid therapy group, $40 \mathrm{mg} /$ day of prednisolone was administered for 8 weeks, which was then tapered to $30 \mathrm{mg} /$ day for 8 weeks, $25 \mathrm{mg} /$ day for 8 weeks, $20 \mathrm{mg} /$ day for 8 weeks, and $10-15 \mathrm{mg} /$ day for 80 weeks. The total duration of 
Table 2 The natural history of patients with mild or early-stage IgA nephropathy
Table 3 Oral steroid therapy and intravenous steroid pulse therapy
$C C r$ creatinine clearance, $n s$ not significant

\begin{tabular}{lllll}
\hline & \multicolumn{2}{l}{ Shen et al. } & & Szeto et al. \\
\hline $\begin{array}{llll}\text { Daily proteinuria } \\
\text { Observation period }\end{array}$ & $<0.03 \mathrm{~g}$ & $>0.03,<0.3 \mathrm{~g}$ & Total $(<0.3 \mathrm{~g})$ & $<0.4 \mathrm{~g}$ \\
Number of patients & 50 & 85 & $92 \pm 28 \mathrm{months}$ & $84(14-180)$ months \\
Disappearance of hematuria & $22 \%$ & $6 \%$ & 135 & 72 \\
Increased proteinuria $(>1.0 \mathrm{~g})$ & $6 \%$ & $42 \%$ & $12 \%$ & $14 \%$ \\
Hypertension & $12 \%$ & $44 \%$ & $29 \%$ & $33 \%$ \\
Decreased kidney function & $4 \%$ & $29 \%$ & $32 \%$ & $19 \%$ \\
\hline
\end{tabular}

\begin{tabular}{lll}
\hline & Kobayashi et al. & Pozzi et al. \\
\hline Study design & Retrospective cohort study & Randomized controlled trial \\
Treatment groups & Oral steroid versus control & Steroid pulse versus control \\
Daily proteinuria & $1.0-2.0 \mathrm{~g}$ & $1.0-3.5 \mathrm{~g}$ \\
$\mathrm{CCr}$ & $85 \pm 14$ versus $88 \pm 13$ & $70-111 \mathrm{ml} / \mathrm{min}(\mathrm{mean} 91)$ \\
$\mathrm{CCr}(\geq 70 \mathrm{ml} / \mathrm{min})$ & Renal survival rate: 100 versus & Non-progression rate: \\
& $80 \%$ at 5 years $(\mathrm{ns})$ & 97 versus $53 \%$ at 10 years $(p=0.0003)$ \\
& 80 versus $34 \%$ at 10 years & Urinary complete remission rate: $\sim 10 \%$ \\
& $(p<0.001)$ & in the steroid pulse group \\
\hline
\end{tabular}

prednisolone therapy was 2 years, after which patients were treated with only the same antiplatelet drugs that the control group received. In the control group, patients had a renal survival rate at 5 and 10 years of 84 and $34 \%$, respectively. On the other hand, in the steroid therapy group, the renal survival rate at 5 and 10 years in patients was 100 and $80 \%$, respectively (compared to control group: $p<0.001)$. They concluded that patients with early-stage IgA nephropathy, with proteinuria between 1.0 and $2.0 \mathrm{~g} /$ day and $\mathrm{CCr}>70 \mathrm{ml} / \mathrm{min}$, had a durable response to oral steroid therapy at 10 years (Table 3 ).

\section{Does methylprednisolone pulse therapy preserve kidney function?}

Pozzi et al. [8] demonstrated the efficacy of steroid pulse therapy for patients with $\operatorname{IgA}$ nephropathy with daily proteinuria in the range of $1.0-3.5 \mathrm{~g}$ and serum creatinine $<1.5 \mathrm{mg} / \mathrm{dl}$. In 86 patients with biopsy-proven $\operatorname{IgA}$ nephropathy diagnosed between 1987 and 1995, 43 patients were randomized to steroid pulse therapy and 43 to nonsteroid (antiplatelet) therapy. Patients in both groups were balanced with respect to age (38 vs. 40), the presence of hypertension (14/43 vs. 15/43), daily proteinuria (1.6-2.4 vs. $1.4-2.4 \mathrm{~g} / \mathrm{day}), \mathrm{CCr}$ (70-111 vs. $72-112 \mathrm{ml} / \mathrm{min})$, and percentage of glomerular sclerosis (0-25 vs. 5-26\%); these patients are similar to the patients in the study by Kobayashi et al. Pozzi et al. defined renal outcome as the primary endpoint, measured as the doubling of baseline serum creatinine, and the reduction of urinary protein as the secondary endpoint, but did not evaluate parameters of renal function such as $\mathrm{CCr}$ or GFR or the renal survival rate. The percentage of non-progressive patients at 10 years was $97 \%$ in the steroid pulse therapy group and 53\% in the control group. Although they did not specifically evaluate CR, approximately $10 \%$ of patients receiving steroid pulse therapy reached CR. Pozzi et al. suggested that steroid pulse therapy is efficacious in patients with IgA nephropathy with $\mathrm{CCr}>70 \mathrm{ml} / \mathrm{min}$ (mean $90 \mathrm{ml} / \mathrm{min}$ ) and proteinuria between 1.0 and $3.5 \mathrm{~g} /$ day (Table 3 ).

\section{Does tonsillectomy stop the progression of renal failure?}

Rasche et al. [9] reported that tonsillectomy showed no efficacy in a retrospective cohort study in 1999. Of 55 patients diagnosed with $\operatorname{IgA}$ nephropathy from 1968 to 1994, 16 patients received tonsillectomy and 39 patients did not. The patient characteristics were as follows: mean age, 32 (range 23-34) versus 33 (28-34); presence of hypertension, $14 / 16$ versus $16 / 39$; daily proteinuria $>1.5 \mathrm{~g}$, 9/16 versus $25 / 39$; mean serum creatinine $\pm \mathrm{SD}, 2.4 \pm 2.8$ versus $1.6 \pm 0.9 \mathrm{mg} / \mathrm{dl}$; serum creatinine $>1.7 \mathrm{mg} / \mathrm{dl}$, 4/16 versus $15 / 39$. The $\mathrm{CCr}$ was estimated to be $<70 \mathrm{ml} / \mathrm{min}$, a level below which Kobayashi et al. found oral steroid therapy not to be efficacious. The renal survival rates of 
Table 4 A retrospective cohort study of tonsillectomy

\begin{tabular}{llll}
\hline & Rasche et al. & Xie et al. & Chen et al. \\
\hline Treatment groups & Tonsillectomy versus control & Tonsillectomy versus control & Tonsillectomy versus control \\
Daily proteinuria & $(>1.5 \mathrm{~g})$ & $0.91 \pm 1.12$ versus $1.09 \pm 1.43$ & $0.973 \pm 0.924$ versus $1.17 \pm 1.02$ \\
& $9 / 16$ versus $25 / 39$ & & $(>1.0 \mathrm{~g}) 19 / 54$ versus $23 / 58$ \\
$\mathrm{sCr}$ & $2.4 \pm 2.8$ versus $1.6 \pm 0.9$ & $1.07 \pm 0.27$ versus $1.07 \pm 0.31$ & $1.08 \pm 0.33$ versus $1.07 \pm 0.275$ \\
$\mathrm{CCr}(\geq 70 \mathrm{ml} / \mathrm{min})$ & Not available & Renal survival rate: 98 versus $89 \%$ & CR rate: 46.3 versus $27.5 \%(p=0.04)$ \\
& & at 10 years $(\mathrm{ns})$ & Relapse rate: 38.9 versus $48.3 \%$ \\
& & 90 versus $63.8 \%$ at 20 years & $(p=0.317)$ \\
& & (efficacy at 20 years; $p<0.05)$ & Not improved rate: 16.7 versus $34.5 \%$ \\
& & $(p=0.031)$ \\
& & & ESRD at less than 15 years: 3.7 versus \\
& & & $12.1 \%(p=0.059)$ \\
& & & Not available
\end{tabular}

$s C r$ serum creatinine, $C C r$ creatinine clearance, $C R$ clinical remission, ESRD end-stage renal disease, $n s$ not significant

both groups at 5 years were between $60 \%$ and $70 \%$ and at 10 years were between $40 \%$ and $60 \%$, with no significant differences between both groups. They concluded that tonsillectomy did not prevent a progressive course in patients with IgA nephropathy (Table 4).

On the other hand, Xie et al. [10] demonstrated the efficacy of tonsillectomy with an observation period of 20 years. They analyzed the data from a retrospective cohort study that included 48 patients who received tonsillectomy and 70 patients who did not receive tonsillectomy. The mean age $\pm \mathrm{SD}$ was $30 \pm 11$ versus $34 \pm 12$ years, daily proteinuria $0.91 \pm 1.12$ versus $1.09 \pm 1.43 \mathrm{~g}$, and serum creatinine was $1.07 \pm 0.27$ versus $1.07 \pm 0.31 \mathrm{mg} / \mathrm{dl}$. These patients correspond to an earlier or milder stage than those in the study by Rasche et al. The renal survival rates of the tonsillectomy and nontonsillectomy groups at 10 years were $98 \%$ and $89 \%$, respectively, with no statistically significant difference; however, the renal survival rates at 20 years were $90 \%$ and $63.8 \%$, respectively $(p<0.05)$. They summarized that tonsillectomy improved renal survival in IgA nephropathy patients 20 years later (Table 4).

In 2007, Chen et al. [11] investigated the efficacy of tonsillectomy in terms of long-term $\mathrm{CR}$ and renal survival in Chinese patients with IgA nephropathy. They performed a 130-month retrospective case-control study of 112 patients with idiopathic biopsy-proven $\operatorname{IgA}$ nephropathy from 1983 to 1999 . There were 54 patients who underwent tonsillectomy and 58 patients who did not. The CR rate was $46.3 \%$ in patients with tonsillectomy and $27.6 \%$ in those without tonsillectomy during the follow-up period that lasted a mean $\pm \mathrm{SD}$ of $130 \pm 50.3$ months (range 60-276 months). The Kaplan-Meier analysis showed no significant difference in renal survival rates between patients with and without tonsillectomy $(p=0.059)$. Since the $p$ value was 0.059 with an observation period of 15 years, differences in the renal survival rate with versus without tonsillectomy may become significant if the observation period were extended to over 20 years (Table 4).

\section{Does TSP induce CR?}

In 2001, Hotta et al. [2] proposed TSP as a new approach that can induce CR in IgA nephropathy. They analyzed 329 patients with IgA nephropathy from 1977 to 1995. The patient profile was as follows: age (mean $\pm \mathrm{SD}$ ), $36.1 \pm 12.8$ years; daily proteinuria, $1.40 \pm 1.09 \mathrm{~g}$; serum creatinine, $1.14 \pm 0.48 \mathrm{mg} / \mathrm{dl}$. There was a correlation between serum creatinine levels and urinary remission rates. In patients with serum creatinine $<0.8 \mathrm{mg} / \mathrm{dl}$, the urinary complete remission rate was $55 \%$ in men and $65 \%$ in women. In patients with serum creatinine between 0.9 and $1.0 \mathrm{mg} / \mathrm{dl}$, it was $55 \%$ in both men and women, and in patients with serum creatinine between 1.1 and $1.3 \mathrm{mg} / \mathrm{dl}$, it was $50 \%$ in men and $30 \%$ in women. Male and female patients with serum creatinine $>1.4 \mathrm{mg} / \mathrm{dl}$ had a urinary complete remission rate of approximately $20 \%$. These results suggest that patients with serum creatinine $>1.4 \mathrm{mg} / \mathrm{dl}$ are resistant to several types of therapy, including steroid therapy and TSP. In a Cox regression analysis with 13 variables, serum creatinine $<1.3 \mathrm{mg} / \mathrm{dl}$, daily proteinuria between 0.5 and $1.5 \mathrm{~g}$, histological score (the index of glomerular lesion, calculated by the degree of mesangial proliferation and sclerosis) $<2.00$, steroid pulse therapy, and tonsillectomy were identified as prognostic factors for urinary complete remission. A comparison of the CR rate with TSP and steroid therapy found TSP to be superior (59.7 vs. $35.3 \% ; p<0.01)$ [8] (Table 5). 
Table 5 A retrospective cohort study of tonsillectomy plus steroid pulse (TSP) therapy

\begin{tabular}{|c|c|c|}
\hline & Hotta et al. & Miura et al. \\
\hline Study design & Retrospective cohort study & Multicenter retrospective study \\
\hline Patients' background & $\begin{array}{l}\text { Daily proteinuria: mean } \pm \text { SD: } 1.38 \pm 1.17 \mathrm{~g} \\
\mathrm{sCr}: 0.96 \pm 0.22 \mathrm{mg} / \mathrm{dl}\end{array}$ & \\
\hline $\mathrm{CCr}(>70 \mathrm{ml} / \mathrm{min})$ & TSP versus steroid: CR rate: 59.7 versus $35.3 \% ; p<0.01$ & $\begin{array}{l}\text { CR rate: } 54.1 \% \\
\text { CR versus non-CR: } \\
\text { Years from diagnosis until TSP therapy: mean } \pm \mathrm{SD} \\
5.3 \pm 5.2 \text { versus } 6.9 \pm 6.8(p=0.02) \\
\text { Daily proteinuria } 0.8 \pm 0.8 \text { versus } 1.5 \pm 1.6(p<0.0001) \\
\text { sCr } 0.87 \pm 0.34 \text { versus } 0.99 \pm 0.40(p=0.006)\end{array}$ \\
\hline $\mathrm{CCr}(<70 \mathrm{ml} / \mathrm{min})$ & $\begin{array}{l}\text { Sato et al. } \\
\text { Retrospective cohort study } \\
\text { TSP versus steroid versus control } \\
\text { Daily proteinuria: mean } \pm \text { SD: } \\
2.2 \pm 1.9 \text { versus } 1.9 \pm 0.9 \text { versus } 0.9 \pm 0.6 \\
\text { CCr: } 45.0 \pm 15.1 \text { versus } 44.4 \pm 14.9 \text { versus } 48.6 \pm 19.7 \\
\text { Renal survival rate at } 8 \text { years: } \\
82.8 \text { versus } 51.0 \text { versus } 45.1 \%: p=0.017 \\
\text { (No significant difference in patients with } \mathrm{sCr}>2.0 \mathrm{mg} / \mathrm{dl} \text { ) }\end{array}$ & Not available \\
\hline
\end{tabular}

$s C r$ serum creatinine, $C C r$ creatinine clearance, $C R$ clinical remission

Table 6 Prospective controlled trials

\begin{tabular}{lll}
\hline & Komatsu et al. & Miyazaki et al. \\
\hline Study design & Prospective controlled trial & Randomized controlled trial \\
Treatment groups & TSP versus steroid pulse & TSP (40 patients) versus steroid pulse (40 patients) \\
Daily proteinuria (mean $\pm \mathrm{SD})$ & $1.06 \pm 1.01$ versus $1.41 \pm 1.05$ & Between 1.0 and $3.5 \mathrm{~g}$ \\
$\mathrm{sCr}$ & $0.72 \pm 0.29$ versus $0.84 \pm 0.30$ & $\mathrm{sCr}<1.5 \mathrm{mg} / \mathrm{dl}$ \\
$\mathrm{CCr}(>70 \mathrm{ml} / \mathrm{min})$ & $\mathrm{CR}$ rate: & Forthcoming \\
& $21 / 34(61.8 \%)$ versus $3 / 17(17.6 \%)$ & \\
& $(p<0.001)$ & \\
\hline
\end{tabular}

$T S P$ tonsillectomy plus steroid pulse, $R C T$ randomized controlled trial, $s C r$ serum creatinine, $C C r$ creatinine clearance, $C R$ clinical remission

In 2002, Sato et al. [12] evaluated the efficacy and limitations of TSP in patients with advanced IgA nephropathy. TSP is superior to steroid therapy or antiplatelet therapy in terms of 8 -year renal survival rates $(82.8$ vs. 51.0 vs. $45.1 \%$, respectively); however, there was no significant difference among patients whose baseline serum creatinine was $>2.0 \mathrm{mg} / \mathrm{dl}$. They recommended initiating TSP before serum creatinine reaches $2.0 \mathrm{mg} / \mathrm{dl}$ (Table 5).

In 2010, Kawaguchi et al. [13] retrospectively analyzed 388 patients diagnosed with $\operatorname{IgA}$ nephropathy by renal biopsy between 1987 and 2000 who presented with hematuria and minimal proteinuria $(<0.5 \mathrm{~g} /$ day $)$ at baseline. Patients treated with TSP had a significantly higher rate of CR than patients who were not treated with tonsillectomy or pulsed steroids in both an unadjusted Cox model [hazard ratio (HR) 5.51; 95\% confidence interval
(CI) 3.33-9.12; $p<0.001]$ and one adjusted for age, sex, estimated GFR, index of glomerular lesion, systolic blood pressure, immunoglobulin A, 24-h urinary protein excretion, urinary red blood cells, comorbidities, and medication (HR 4.65; 95\% CI 2.43-8.88; $p<0.001$ ). TSP significantly increased the probability of $\mathrm{CR}$ in $\operatorname{IgA}$ nephropathy patients with minimal proteinuria (Table 5).

\section{Do all patients with IgA nephropathy respond to TSP?}

Miura et al. [3] evaluated the efficacy of TSP in a multicenter retrospective cohort study. After collecting data from many hospitals in Japan, they first identified groups with higher and lower CR rates and compared patient characteristics between the two groups. There was a 
significant difference in age at onset $(p=0.05)$, daily proteinuria $(p=0.02)$, total protein $(p=0.02)$, and pathological grade $(p=0.009)$ between the higher CR rate group and the lower CR rate group. In the 303 patients included in their study, 164 (54.1\%) patients reached CR 1 year after TSP. The comparison between patients who reached CR and those who did not achieve CR revealed significant differences in the number of years from diagnosis until TSP $(p=0.02)$, daily proteinuria $(p<0.0001)$, serum creatinine $(p=0.006)$, and pathological grade $(p=0.0006)$. Miura et al. showed that TSP was effective for patients with early-stage disease if performed within 5 years at onset, with daily proteinuria $<1.1 \mathrm{~g}$ and serum creatinine $<1.5 \mathrm{mg} / \mathrm{dl}$ (Table 5).

\section{Do prospective controlled studies confirm the efficacy of TSP?}

Komatsu et al. [14] reported the results of a prospective trial of TSP in 2008. They compared the data on patients treated with TSP $(n=35)$ and patients who received only steroid pulse therapy $(n=20)$. The mean daily proteinuria \pm SD was $1.06 \pm 1.01$ versus $1.41 \pm 1.05 \mathrm{~g}$, and mean serum creatinine $\pm \mathrm{SD}$ was $0.72 \pm 0.29$ versus $0.84 \pm 0.30 \mathrm{mg} /$ $\mathrm{dl}$, respectively. The $\mathrm{CR}$ rate at 24 months was 61.8 versus $17.6 \%(p<0.001)$. The authors concluded that TSP can induce $\mathrm{CR}$ in patients with $\operatorname{IgA}$ nephropathy with daily proteinuria of approximately $1.0 \mathrm{~g}$ and serum creatinine $<1.1 \mathrm{mg} / \mathrm{dl}$. However, their study was limited since it was not randomized, and the patients' baseline data differed slightly between the two treatment groups (Table 6).

Miyazaki et al. [15] performed a randomized controlled trial (RCT) of TSP in Japan, with the following inclusion criteria: daily proteinuria between 1.0 and $3.5 \mathrm{~g}$, serum creatinine $<1.5 \mathrm{mg} / \mathrm{dl}$, and chronic tonsillitis. Although detailed data will be available in the near future, preliminary data from this trial suggest that TSP is a promising treatment for inducing CR of IgA nephropathy, and might become first-line treatment for IgA nephropathy (Table 6).

\section{Perspectives on the treatment of IgA nephropathy}

After the details of the RCT on TSP are released, several clinical questions will emerge. Which patients with $\operatorname{IgA}$ nephropathy are ideal candidates for TSP? At what level of daily urinary protein is a kidney biopsy indicated? Does early intervention really improve prognosis? Can $\operatorname{IgA}$ nephropathy recur after TSP? We have to answer these questions.

In order to obtain clinical evidence within a short 5-year period, we propose a clinical trial enrolling patients with daily proteinuria $<1.0 \mathrm{~g}$ and $\mathrm{GFR}$ or $\mathrm{CCr}>90 \mathrm{ml} / \mathrm{min}$ whose primary endpoints are the $\mathrm{CR}$ rate and the proportion of patients whose GFR or $\mathrm{CCr}$ decrease to $\leq 70 \mathrm{ml} / \mathrm{min}$ (rate of decline in renal function). Patients should be divided randomly into three groups: antiplatelet drugs, steroid pulse therapy according to the protocol in Pozzi et al., and TSP according to the protocol of Hotta et al. This trial should be open to international investigators. This proposed RCT is essential for studying TSP for early stages of $\operatorname{IgA}$ nephropathy. Alternatively, prospective cohort studies are needed to evaluate the renal survival rate after 20 years. Finally, as the recurrence of IgA nephropathy after renal transplantation is a significant issue, RCTs involving TSP before transplantation will provide information on recurrence of IgA nephropathy. The results of the current RCT in Japan will propel us into a new era of treatment for IgA nephropathy.

Acknowledgments This work was supported by a grant (to H.I.) from the Progressive Renal Diseases Research Project of the Ministry of Health, Labour and Welfare of Japan.

Conflict of interest None declared.

Open Access This article is distributed under the terms of the Creative Commons Attribution Noncommercial License which permits any noncommercial use, distribution, and reproduction in any medium, provided the original author(s) and source are credited.

\section{References}

1. Berger J, Hinglais N. Les depots intercapilaires d'IgA-IgG. J Urol Nephrol. 1968;74:694-5.

2. Hotta O, Miyazaki M, Furuta T, Tomioka S, Chiba S, Horigome I, et al. Tonsillectomy and steroid pulse therapy significantly impact in patients with $\operatorname{Ig}$ A nephropathy. Am J Kidney Dis. 2001;38:736-42.

3. Miura N, Imai H, Kikuchi S, Hayashi S, Endoh M, Kawamura T, et al. Tonsillectomy and steroid pulse (TSP) therapy for patients with IgA nephropathy: a nationwide survey of TSP therapy in Japan and an analysis of the predictive factors for resistance to TSP therapy. Clin Exp Nephrol. 2009;13:460-6.

4. Chauveau D, Droz D. Follow-up evaluation of the first patients with $\operatorname{Ig}$ A nephropathy described at Necker Hospital. Contrib Nephrol. 1993;104:1-5.

5. Szeto CC, Lai FM, To KF, Wong TY, Chow KM, Choi PC, et al. The natural history of immunoglobulin A nephropathy among patients with hematuria and minimal proteinuria. Am J Med. 2001;110:434-7.

6. Shen P, He L, Li Y, Wang Y, Chan M. Natural history and prognostic factors of IgA nephropathy presented with isolated microscopic hematuria in Chinese patients. Nephron Clin Pract. 2007;106:c157-61.

7. Kobayashi Y, Hiki Y, Kokubo T, Horii A, Tateno S. Steroid therapy during the early stage of progressive IgA nephropathy. A 10-year follow-up study. Nephron. 1996;72:237-42.

8. Pozzi C, Andrulli S, del Vecchio L, Melis P, Fogazzi GB, Altieri $\mathrm{P}$, et al. Corticosteroid effectiveness in IgA nephropathy: long- 
term results of a randomized, controlled trial. J Am Soc Nephrol. 2004;15:157-63.

9. Rasche FM, Schwart A, Keller F. Tonsillectomy does not prevent a progressive course in $\operatorname{IgA}$ nephropathy. Clin Nephrol. 1999;51:147-52.

10. Xie Y, Nishi S, Ueno M, Imai N, Sakatsume M, Narita I, et al. Relationship between tonsils and IgA nephropathy as well as indication of tonsillectomy. Kidney Int. 2004;65:1135-44.

11. Chen Y, Tang Z, Wang Q, Yu Y, Zeng C, Chen H, et al. Longterm efficacy of tonsillectomy in Chinese patients with $\operatorname{IgA}$ nephropathy. Am J Nephrol. 2007;27:170-5.

12. Sato M, Hotta O, Tomioka S, Chiba S, Miyazaki M, Noshiro H, et al. Cohort study of advanced $\operatorname{IgA}$ nephropathy: efficacy and limitations of corticosteroids with tonsillectomy. Nephron Clin Pract. 2003;93:c14-137.
13. Kawaguchi T, Ieiri N, Yamazaki S, Hayashino Y, Gillespie B, Miyazaki M, et al. Clinical effectiveness of steroid pulse therapy combined with tonsillectomy in patients with immunoglobulin A nephropathy presenting glomerular haematuria and minimal proteinuria. Nephrology. 2010;15:116-23.

14. Komatsu H, Fujimoto S, Hara S, Sato Y, Yamada K, Kitamura K. Effect of tonsillectomy plus steroid pulse therapy on clinical remission of IgA nephropathy: a controlled study. Clin J Am Soc Nephrol. 2008;3:1301-7.

15. Miyazaki Y, Yoshimura M, Kimura K, Tomino Y, Kawamura T. Tonsillectomy plus steroid pulse therapy in IgA nephropathy: a randomized, controlled trial. The President special symposium for "Treatment of $\operatorname{IgA}$ nephropathy: tonsillectomy and steroid pulse therapy". The 54th Annual Meeting of the Japanese Society of Nephrology in 2011. 